\title{
Simulation to recover niobium and tantalum from the tin slags of the Penouta mine: a case study
}

\author{
Ricardo Magdalena ${ }^{1 *}$, Alicia Valero ${ }^{1}$, Guiomar Calvo ${ }^{1}$, Francisco J. Alguacil ${ }^{2}$, Félix Antonio López Gómez ${ }^{2}$
}

${ }^{1}$ CIRCE Institute, Universidad de Zaragoza, Campus Rio Ebro. C/ Mariano Esquillor Gómez, 15, 50018 Zargoza; Spain; rmagdalena@unizar.es (R.M.); aliciavd@unizar.es (A.V.); gcalvose@unizar.es (G.C.)

2 Centro Nacional de Investigaciones Metalúrgicas (CENIM), Consejo Superior de Investigaciones Científicas (CSIC), Avda. Gregorio del Amo,8, 28040 Madrid, Spain; f.lopez@csic.es (F.A.L.) fjalgua@cenim.csic.es (F.J.A.)

* Correspondence: rmagdalena@unizar.es

\begin{abstract}
Demand for niobium and tantalum is increasing exponentially as these are essential ingredients for the manufacture of, among others, capacitors in technological devices and ferroniobium. Mine tailings rich in such elements could constitute an important source of $\mathrm{Nb}$ and $\mathrm{Ta}$ in the future and so alleviate potential supply risks. This paper evaluates the possibility of recovering niobium and tantalum from the slags generated during the tin beneficiation process of mine tailings from the old Penouta mine, located in Spain. To do so, a simulation of the processes that would be required to beneficiate and refine both elements is carried out. After tin carbothermic reduction, the slags are sent to a hydrometallurgical process where at the end niobium oxide and tantalum oxide are obtained. Reagents, water and energy consumption, in addition to emissions, effluents and product yields are assessed. Certain factors were identified as critical, and recirculation was encouraged in the model to maximize production and minimize reagents use and wastes. With this simulation, considering 3000 production hours per year, the metal output from the tailings of the old mine could cover around $1 \%$ and $7.4 \%$ of the world annual $\mathrm{Nb}$ and Ta demand, respectively.
\end{abstract}

Keywords: coltan; niobium; tantalum; critical raw materials; technological metals; mineral processing.

\section{Introduction}

Currently, our society relies on the use of different materials, and in particular metals, for technology development [1]. The 20th century has been characterized by a drastic increase in global material extraction and this trend is far from changing in the 21st century [2]. In the last decades we have seen a considerable increase in the demand of certain metals that are needed to manufacture electric and electronical components, some of which are used in renewable energies, electric vehicles and digital devices [3,4]. These devices have indeed become a part of our daily life and this trend is expected to continue over the coming years [5].

There are many factors that are driving the importance of technology in society, such as customer requirements. Some examples are the demand of more efficiency and better experiences, the Internet of Things (IoT), Machine Learning (ML) or Artificial Intelligence among others [5]. And this demand has to be combined with the one coming from clean technologies. In the "Mission Innovation" signed in Paris in 2015, 20 countries agreed to promote the acceleration of innovation on clean energies, to make them more affordable and accessible to all and achieve the goals of the Paris Agreement and pathways to net zero [6]. This, in turn, increased the investment of governments and deployment of renewable energies, a type of technology that requires a considerable amount of critical materials in the manufacturing process $[7,8]$. 
In the end, the use and applications of electric and electronic equipment (EEE), both in renewable energies and in other fields, is steadily growing as innovation has made devices more efficient [9]. This development usually implies an increase in the number, and variety, of the metals used $[10,11]$. On one hand, some metals have specific properties which makes them unique for certain devices [12]. On the other hand, as the sales of mobile phones, tablets and other devices increase, a larger amount of metals is needed to produce them $[4,13]$. As a consequence, the amount of e-wastes is also considerably increasing, being Europe an example, with a growth between 3-5\% per year [14].

In the case of certain metals such as niobium $(\mathrm{Nb})$ or tantalum $(\mathrm{Ta})$, even if they are used in small quantities on each device, the total amount of metals used at world level is considerable. Moreover, niobium is an essential metal for the manufacture of ferroalloys. The most important of these is ferroniobium, which contains between $60 \%-70 \%$ niobium [15]. It is also an element that forms part of high-strength low alloy (HSLA) steels [16].Both metals were discovered centuries ago, still, they have only begun to be used in the last decades for different applications. Currently, both are crucial for EEE and renewable energies. Their future availability could be dangerously compromised as the primary sources, meaning the places where they are mined, are limited [17]. In fact, they are considered critical by many countries and institutions, as their current and future availability, or the concentration of supply, could put at risk many economies [18-20].

In order to meet the ever-growing demand, alternative sources of niobium and tantalum are urgently required to avoid depletion and promote more sustainable mining. The use of rich $\mathrm{Nb}$ and Ta rich tailings from old mines could constitute a promising alternative. For this reason, this paper explores the potential recovery of these two metals from the zinc tailings of an abandoned mine in Spain. To that end, a virtual pilot plan modeled with HSC chemistry was set and optimized to maximize its efficiency and identify costs of chemicals, water, electricity or emissions.

\section{Niobium and tantalum production and availability}

According to the United States of Geological Survey (USGS), Brazil is the largest niobium producer at world level, and this trend has been maintained over the last few decades (Figure 1). Only in 2020, this single country was responsible of $91 \%$ of the niobium world production, followed by Canada (8\%) [21]. Niobium reserves are also mainly concentrated in Brazil (95\%) and Canada (3.5\%), while the remaining are located in Angola, Australia and South Africa, among others [22].

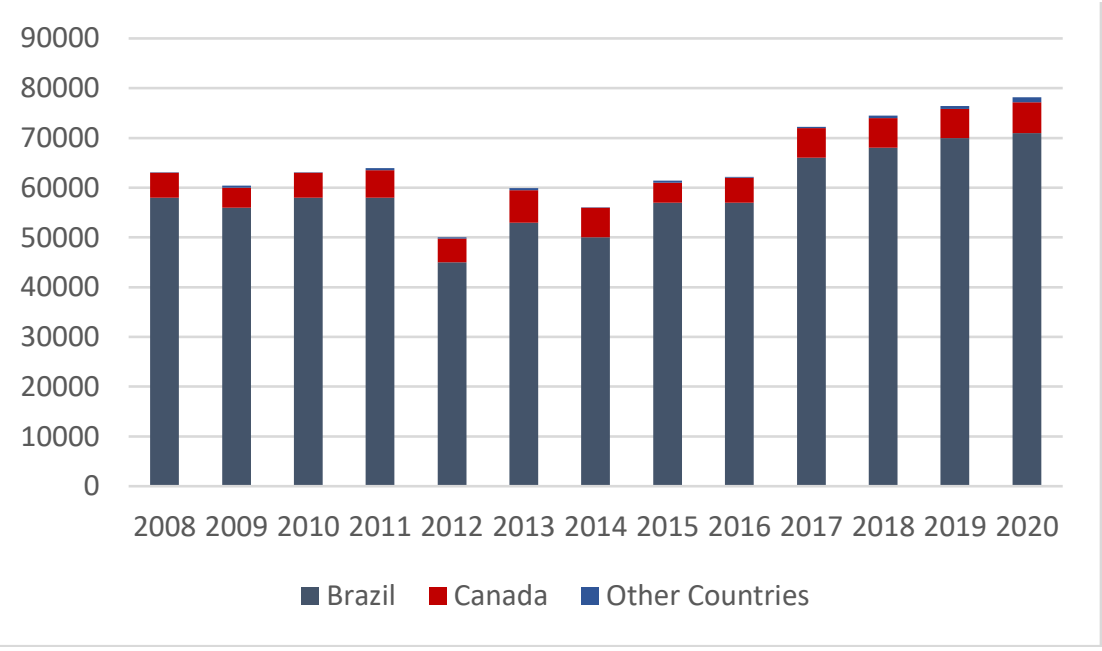

Figure 1. Historical production of niobium in metric tons [21].

As for tantalum, one of the most valuable ores from which this metal is extracted is coltan. Coltan is a mixture of two minerals, tantalite, where tantalum predominates, and columbite, where niobium predominates. For this reason, coltan is also an important source of niobium. 
More than $60 \%$ of tantalum reserves are hosted in Democratic Republic of Congo (DRC), while the remaining are in Brazil and Australia [23]. DRC alone was responsible for $40 \%$ of the total world production in 2020 [21]. Historical tantalum production can be seen in Figure 2, clearly showing the predomination of Africa over other regions of the world.

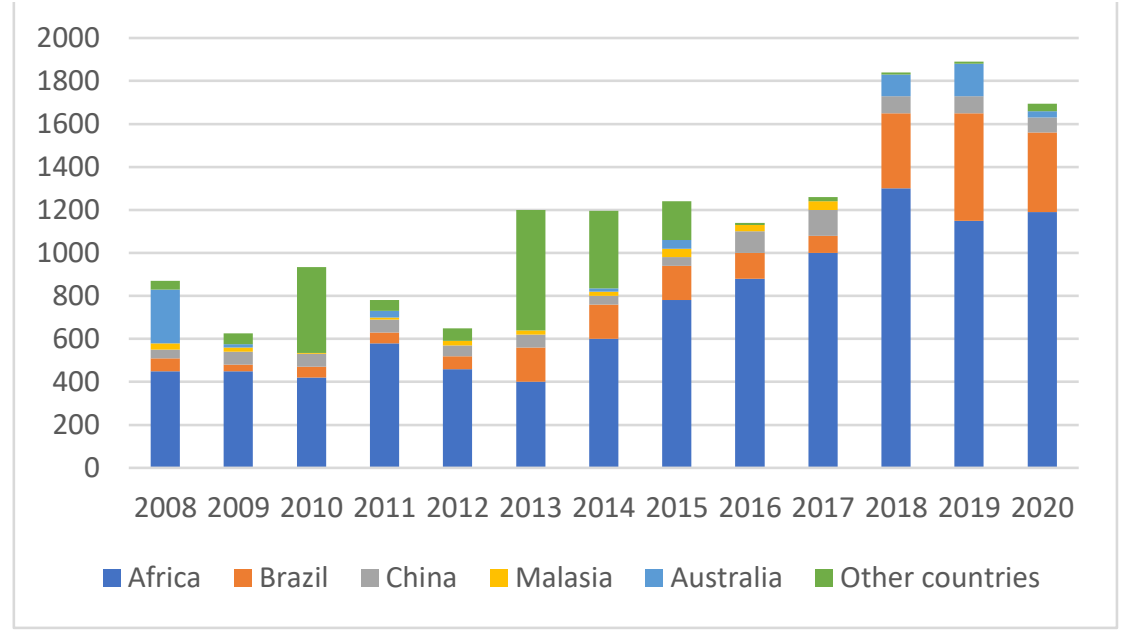

Figure 2. Historic production of tantalum in metric tons [21].

Africa plays thus a key role in tantalum production since it has been responsible for more than the $60 \%$ of the global production on average in the last years. Before 2008, Australia had an important market share, reaching almost $50 \%$ of the total world production [24]. However, with the worldwide crisis that occurred in 2008, some of the biggest mines in Australia suspended their activity due to financial difficulties, reducing its production share in the global market in the following years [25].

The concentration of supply in DRC and Rwanda, countries that arguably do not respect human and works rights, is a global concern $[26,27]$. Some of the most powerful companies agreed to obtain every metal used in their devices from a trustworthy resource [28]. To that end, a certificate can be provided to the end-user, claiming that the device has been manufactured by companies that respect human and work rights, from the extraction of the mineral until the device is sold [26].

Another alternative to overcome this situation of supply concentration is to find new ways to obtain niobium and tantalum or new sources. For this endeavour, the slags generating during the tin beneficiation process in the Penouta mine (located in Spain) will be analysed as a future source for both metals. Different geological studies were carried out but the mine ceased its activity in the 1980s due to a decrease in tin price and depletion of higher ore grade zones.

\subsection{Penouta mine}

The history of the Penouta mine goes back to the beginning of the $20^{\text {th }}$ century, when the area was first exploited and small amounts of cassiterite were extracted. Mining activity was then resumed in the 1960s and until 1971, becoming one of the most important tin mines in Europe. During the last years of activity, around 1,600,000 t of rock were extracted, containing around $640 \mathrm{t}$ of cassiterite and $170 \mathrm{t}$ of tantalite concentrate [29]. This deposit consists of a greisenized, altered and kaolinized granite mass enclosed in metamorphic rock, with disseminated cassiterite and columbo-tantalite [30].In the $21^{\text {st }}$ century new studies were carried out. Between the two zones analysed, resources estimates add up to 11,910,402 t of ore, with a Sn and Ta content of 428 and 35 ppm, respectively. In 2020, Strategic Minerals Spain resumed the mining activities in the area, becoming again the only mine in Europe in which concentrates of $\mathrm{Nb}$ and $\mathrm{Ta}$ are recovered, but not yet refined. 


\section{Methodology and data availability}

\subsection{Model for recovering $\mathrm{Nb}$ and Ta from slags}

The aim of this study is to analyse the possibilities of the recovering process of $\mathrm{Nb}$ and Ta from tin slags using a simulation of a metallurgical plant. Similar simulations using the same software to recover metals from common rocks, such as iron, lead, zinc and gold, have been carried out in previous studies [31-33].

As stated before, the Penouta tin mine was selected for the case study. Tin was initially obtained from cassiterite $\left(\mathrm{SnO}_{2}\right)$, containing important concentrations of $\mathrm{Nb}$ and $\mathrm{Ta}$ that could be economically profitable to recover [34]. The slags obtained after the first metallurgical process still have an important concentration of $\mathrm{Nb}$ and $\mathrm{Ta}$. Until now, they have remained in the tailings as they could not be beneficiated when the mine was operating, yet they constitute an valuable source of such commodites.

The processes required for niobium and tantalum recovery were already studied by different authors in previous studies, establishing the initial concentration for the three metals considered [34-37]. As niobium and tantalum, have similar chemical and physical properties, their separation and purification processes are considerably difficult [36]. Still, they can be recovered from the slags generated after a carbothermic reduction $[37,38]$. Additionally, recent investigations driven by research groups at CSIC developed a process at lab scale to recover $\mathrm{Nb}$ and $\mathrm{Ta}$ by solvent extraction from $\mathrm{Sn}-\mathrm{Ta}-\mathrm{Nb}$ mining tailings that has also been the seed of this study [38].

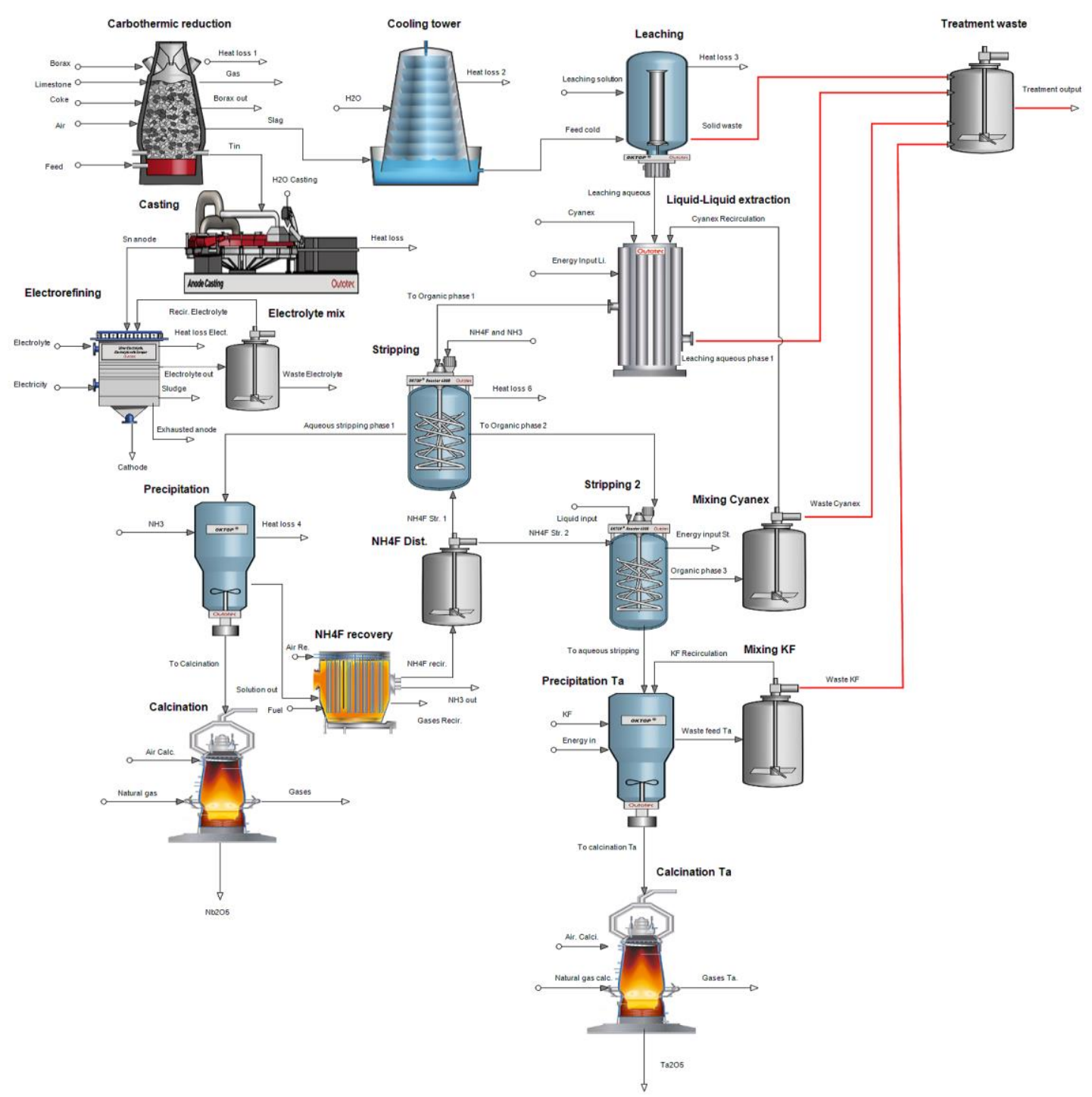

Figure 3. Flowsheet of the process used to recover $\mathrm{Sn}$ along with $\mathrm{Nb}$ and $\mathrm{Ta}$ from the slags. 
Figure 3 shows the flowsheet of the processes used to recover the three metals generated with HSC Chemistry. The process starts with the tailings coming from a particular mine with $\mathrm{Sn}-\mathrm{Nb}-\mathrm{Ta}$, in our case, Penouta. It is important to mention that before the beginning of the process, comminution is needed to reduce the rock coming from the tailings, for this, jaw crusher and ball mills are used. The particle size is then reduced to 200 $\mu \mathrm{m}$ and sent to the feed of the metallurgical process. Next, it is necessary to proceed with pre-concentration in the industrial plant. After mixing the minerals of the feed with some additives, they are sent to the carbothermic reduction to start the purification of metals [37]. Carbothermic reduction is applied to separate Sn from other oxides.

At this point, $\mathrm{Sn}$ is obtained with a concentration higher than $96 \%$, while the slags contains a significant concentration of $\mathrm{Ta}$ and $\mathrm{Nb}, 25 \%$ and $21 \%$, respectively [37]. As the final product should be $99.99 \% \mathrm{Sn}$, it is necessary to apply an electrorefining process in order to increase its concentration. To that end, an electrolyte of $\mathrm{H}_{2} \mathrm{SO}_{4}$ is prepared in order to separate impurities from Sn, increasing its concentration to the desired value [37].

On the other hand, slags are sent to different units to extract $\mathrm{Nb}$ and $\mathrm{Ta}$. The feed is first sent to the leaching unit, obtaining solid wastes and another output in aqueous phase, which ends in the liquid-liquid extraction unit. It is then mixed with organic additives, discarding the leaching aqueous phase and redirecting the organic phase output into the stripping unit. Additionally, $\mathrm{NH}_{3}$ and $\mathrm{NH}_{4} \mathrm{~F}$ are added since this is the unit where $\mathrm{Nb}$ and Ta will be separated. By using these additives, a new enriched $\mathrm{Nb}$ aqueous phase is formed, finishing in the precipitation unit. Meanwhile, the other output, still in organic phase, is sent to a new stripping unit to convert it into an aqueous phase too. It follows precipitation for both feeds, aiming at eliminating any impurities before continuing with the last phase of the process, calcination. Calcination is used to eliminate the undesired water and humidity, recovering at the end of the whole process $\mathrm{Nb}$ with a concentration close to $99 \%$ and Ta with a concentration of $78 \%$.

It is important to mention that there are also several recirculation units and that vast number of reagents are needed for this whole process. To reduce the total use of chemicals, feeds are recirculated and introduced again in the units when possible. One example is the "mixing Cyanex 923" unit, where 95\% of the total Cyanex 923 is recirculated in order to maximize its use. Another one is the "mixing KF" unit. It is not possible to use $100 \%$ of this reagent due to the conditions needed in the extraction of tantalum. For that reason, a recirculation of $65 \%$ is assumed, thereby re-using it as many times as possible.

Other authors have studied the recovery of such elements using different chemicals in order to separate $\mathrm{Ta}$ and $\mathrm{Nb}$ during the leaching and the solvent extraction process $[39,40]$. However, the study proposed in this paper reflects an increase of the recovery ratio in comparison with the literature review, obtaining higher amounts of both minerals at the end of the refining process.

Once the initial model of the treatment plant is ready, a preliminary analysis of the different inputs needed to purify the three main metals present in this mine ( $\mathrm{Sn}, \mathrm{Nb}, \mathrm{Ta}$ ), as well as a thermodynamic analysis for a future implantation of the metallurgy plant, is undertaken.

\section{Results}

To proceed with the scale up of the process validated at lab scale, a specialised software called HSC Chemistry has been used, which allows to assess costs and optimise the processes [41].

To run the simulation, the first step is to determine the amount of rock per hour to be treated. Although different feeds have been analysed, 1 ton per hour (tph) has been chosen as the initial feed. This number is in accordance with the size and capacity of the mine. After setting up all equipments, flows and reactions taken place, the amounts of reagents needed for the whole process (and for each unit) as well as outputs of metals and electricity used, among other factors were obtained, as described in the next sections. 


\subsection{Reagents and water used}

Table 1 shows information about the flow rates of the different reagents introduced in the system.

A vast number and amount of chemicals are used in the aforementioned process to recover $\mathrm{Sn}, \mathrm{Nb}$ and Ta. Nonetheless, sulphuric acid is the most used reagent, with $2.03 \mathrm{t} / \mathrm{h}$. This is something that is consistent with the beneficiation process used, as an electrolyte is needed to process more than $0.5 \mathrm{t} / \mathrm{h}$ of $\mathrm{Sn}$ in order to increase its concentration to $99.99 \%$.

Table 1. Amount of reagents introduced [in $\mathrm{t} / \mathrm{h}]$.

\begin{tabular}{cccccc}
\hline Borax & Limestone & Coke & HF & H $_{2} \mathrm{SO}_{4}$ & Cyanex 923 \\
\hline 0.14 & 0.20 & 0.23 & 0.49 & 2.03 & 0.07 \\
\hline Solvesso & $\mathrm{NH}_{4} \mathbf{F}$ & $\mathrm{NH}_{3}$ & KF & Natural gas \\
\hline 0.12 & 0.11 & 0.66 & 0.03 & 0.03 \\
\hline
\end{tabular}

The type of reagents used in each metallurgical unit has also been analysed (Figure 4). This way, it is possible to compare which reagents are used on each specific part of the whole process and their share with respect to the total use on each unit. Using this figure, the units that could be investigated to minimise the use of chemicals stand out.

In this case, it is possible to see how the carbothermic reduction is the unit where a greater number of different reagents are introduced (borax, limestone and coke). Moreover, the liquid-liquid extraction process also stands out as a crucial unit since the phase changes from aqueous to organic. Specifically, it is the only unit what uses Solvesso (solvent) and Cyanex 923(extraction agent). Additionally, HF is only used in the leaching unit and KF in the precipitation of tantalum. On the other hand, $\mathrm{NH}_{3}$ is used in three different units, stripping 1 and 2 and precipitation.

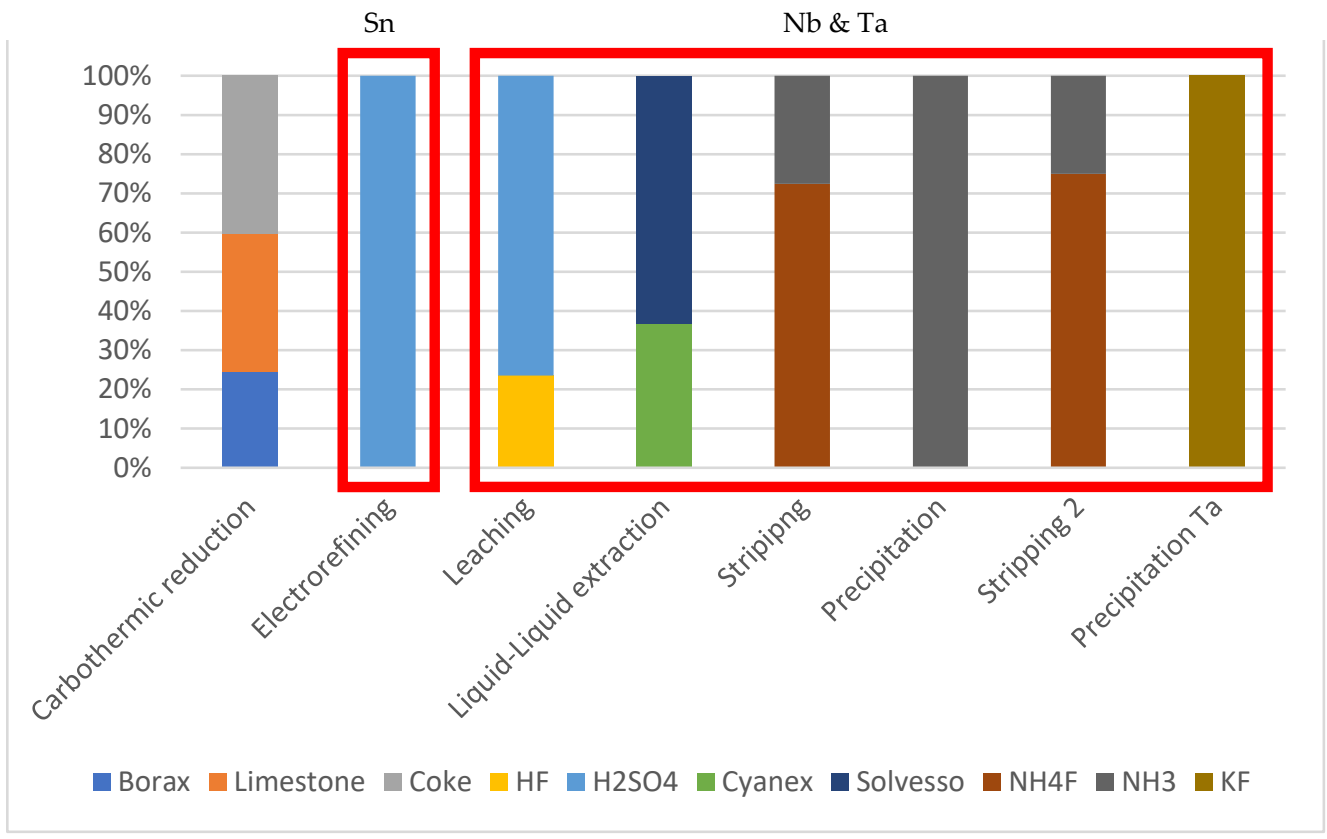

Figure 4. Share of reagents needed in each unit of the treatment and beneficiation process of $\mathrm{Sn}, \mathrm{Nb}$ and Ta.

Among the materials used during the beneficiation process, water is the highest input in the system with almost $12 \mathrm{t} / \mathrm{h}$, which is a common rate used in metallurgical processes [42].

Of these $12 \mathrm{t} / \mathrm{h}$ of water needed, almost half $(5.12 \mathrm{t} / \mathrm{h})$ are used in the electrorefining unit (Figure 5). The second unit where more water is required is in the stripping because of the high volumetric relation between the organic and the aqueous phase. 


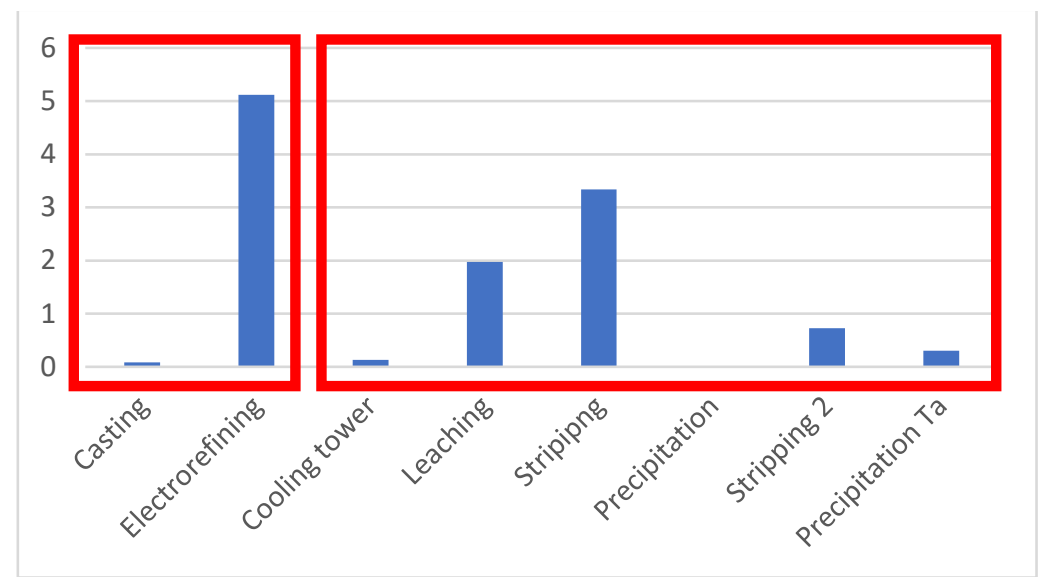

Figure 5. Water requirements in the beneficiation process of $\mathrm{Sn}, \mathrm{Nb}$ and $\mathrm{Ta}$ [in $\mathrm{t} / \mathrm{h}$ ].

\subsection{Metal output}

At the end of the process, the metals obtained are tin, niobium, and tantalum. Table 2 shows how much metal is recovered with a feed of $1 \mathrm{t} / \mathrm{h}$ of ore. The main difference between these metals is that tin is recovered after two metallurgy processes using a very small amount of reagents. A total of 0.50 tons of tin are recovered per hour and considerably lower amounts of $\mathrm{Nb}$ and $\mathrm{Ta}$. On the other side, niobium and tantalum are recovered as by-products. Their initial concentration is very small, and a higher number of processes and chemicals are needed to purify them.

Table 2. Metal output [in $\mathrm{t} / \mathrm{h}]$.

\begin{tabular}{cc}
\hline Metal & Amount \\
\hline $\mathrm{Sn}$ & 0.45 \\
$\mathrm{Nb}$ & 0.03 \\
$\mathrm{Ta}$ & 0.05 \\
\hline
\end{tabular}

\subsection{Electricity consumption and gas emissions}

The electricity required for the hydrometallurgy processes as well as the gases generated during them are also considered in the study.

Electricity is needed during the process to move the blades that are in charge of mixing the reagents with the feed [43]. During the simulation with HSC, it is not possible to directly obtain figures on electricity consumption as this parameter is related to the feed introduced and the size of the units. However, some authors state that an average value could be between 0.05 and $0.1 \mathrm{~kW} / \mathrm{m}^{3}$ [44].

Since the volume of every hydrometallurgy unit is known, it is then possible to calculate the electricity needed for our process, choosing the highest electricity consumption value (see Table 3). 
Table 3. Electricity needed on each unit.

\begin{tabular}{cc}
\hline Unit & Electricity $[\mathbf{k W}]$ \\
\hline Electrolyte mix & 1.062 \\
Leaching & 0.416 \\
Liquid-Liquid extraction & 0.842 \\
Stripping & 0.959 \\
Precipitation & 0.515 \\
Mixing reagents & 0.428 \\
Stripping 2 & 0.858 \\
Mixing Cyanex 923 & 0.421 \\
Precipitation Ta & 1.31 \\
Mixing KF & 1.301 \\
\hline
\end{tabular}

The highest energy values correspond to the units that precipitate and recirculate Ta. This is in line with the results obtained during the simulation, since the volumetric relation between $\mathrm{H}_{2} \mathrm{O}$ and the reagent used to precipitate Ta is very high. Consequently, recirculation units must be similar to the previous units, since the amount of feed introduced is within the same order of magnitude, and therefore, it will have a high energy consumption.

According to some studies, the electricity needed to send tin to electrorefining could be between 150-200 kW/t-tin [45]. Therefore, with the amount of pure Sn obtained in our simulation, the electricity needed would be in the range of 75-100 kW.

As for gaseous emissions, mainly $\mathrm{CO}$ and $\mathrm{CO}_{2}$ are generated predominantly in three units: carbothermic reduction, $\mathrm{Nb}$ calcination, and Ta calcination (Table 4). In the carbothermic reduction, as it is necessary to increase the temperature to $1200^{\circ} \mathrm{C}$ so that the process can occur, $0.23 \mathrm{t} / \mathrm{h}$ (around $24 \%$ of the feed) of coke is introduced, producing 0.84 $\mathrm{t} / \mathrm{h}$ of $\mathrm{CO}_{2}$ emissions to the atmosphere. Additionally, both $\mathrm{Nb}$ calcination and Ta calcination also need a temperature of $1200^{\circ} \mathrm{C}$ to eliminate the humidity from the feeds. In these cases, 0.02 and $0.01 \mathrm{t} / \mathrm{h}$ of natural gas are introduced in the $\mathrm{Nb}$ calcination unit and $\mathrm{Ta}$ calcination unit, respectively. Compared to the emissions of the carbothermic reduction, they have almost negligible gas emissions to the atmosphere.

Table 4. Gases emissions per unit [in $\mathrm{t} / \mathrm{h}$ ].

\begin{tabular}{cccc}
\hline Output Gases & Carbothermic & Calc. Nb & Calc. Ta \\
\hline $\mathrm{CO}$ & 0.06 & 0.003 & 0.005 \\
$\mathrm{CO}_{2}$ & 0.84 & 0.05 & 0.013 \\
\hline
\end{tabular}

\subsection{Analysis of the results}

To analyse the results, the amount of rock extracted from the mine and the metals obtained at the end of the process must be considered. After processing one ton of ore coming from the Penouta mine, around 0.5 tons of metals are recovered, the vast majority corresponding to tin.

As mentioned, several metallurgical processes are needed to purify $\mathrm{Nb}$ and $\mathrm{Ta}$ from that ore. Various reagents must be mixed with the feed to produce changes in the phases and separate them so that they finally end up precipitating in the form of almost pure metal. At the end of the simulation, to obtain $30 \mathrm{~kg}$ of Nb and $50 \mathrm{~kg}$ of Ta, more than 3000 $\mathrm{kg}$ of chemicals have been used to reach full separation. Moreover, the amount of water needed in the process is not negligible either. Around 12,000 kg of water have to be used 
to process one ton of ore, of which around $6,000 \mathrm{~kg}$ are needed in the electrorefining process to purify tin. The rest is used in the remaining processes to concentrate $\mathrm{Nb}$ and $\mathrm{Ta}$.

As seen in Figure 3 and after analysing the costs associated with the reagents, it was determined that different recirculation units should be incorporated. Particularly, we introduced five units that recirculate reagents and water. These units are crucial as the requirements of chemicals could increase up to $50 \%$ if there were no recirculation.

Additionally, a final unit named "treatment waste" was included in the simulation. All the undesired outputs are recirculated to this unit to proceed with a further treatment and decrease the overall environment impact of the plant. Treatment waste unit receives huge amounts of residues from different units, as the simulation discards an elevated quantity of water and reagents.

Table 5 shows the most abundant reagents that reach this unit. This can be used to better understand the importance of waste treatment as more than $8,000 \mathrm{~kg} / \mathrm{h}$ of water are discarded and mixed with other substances.

Table 5. Certain reagents that end in the treatment waste unit [in $\mathrm{kg} / \mathrm{h}]$.

\begin{tabular}{cc}
\hline Variable & Amount \\
\hline $\mathrm{H}_{2} \mathrm{O}$ & 11,510 \\
$\mathrm{HF}$ & 370 \\
$\mathrm{H}_{2} \mathrm{SO}_{4}$ & 2,030 \\
$\mathrm{CaF}_{2}$ & 80 \\
\hline
\end{tabular}

According to the results obtained during the simulation, the percentage of recovery at the end of the process from the rock is $45 \%, 3 \%$ and $5 \%$ for $\mathrm{Sn}, \mathrm{Nb}$ and Ta, respectively. However, if only tin slags are considered, values for $\mathrm{Nb}$ and Ta increase significantly, reaching values close to $50 \%$ for niobium and more than $56 \%$ for tantalum. These values are considerably higher than those that can be found in literature [46].

\section{Discussion and conclusions}

The results obtained from the simulation are very promising since the recovery of niobium and tantalum after tin beneficiation has been demonstrated to be possible. Furthermore, even if the Penouta mine was mainly aimed at obtaining tin, both metals could also be extracted from the slags as by-products with current available technology. Considering that current demand of pure $\mathrm{Nb}$ in 2017 was 6,400 tons while the demand of Ta was 2,079 tons, according to our simulation, the metal output from the mine could represent more than $1 \%$ and $7.4 \%$ of the annual market share for $\mathrm{Nb}$ and $\mathrm{Ta}$, respectively, assuming 3,000 h production hours in a year. These values represent a moderate scenario, since the input introduced could be higher than $1 \mathrm{t} / \mathrm{h}$ of rock depending on the capacity of the mine and ore quality. Additionally, these $3,000 \mathrm{~h}$ of production hours in a year could also increase, depending on different factors such as different working shifts, working days in the year, etc., being able to run the factory many hours during a year.

The main disadvantage found in the simulated process is the amount of chemicals that are required, as well as the use of water in the process. This issue could affect the cost effectiveness of a future processing plant. Additionally, the environment impacts related with all the reagents discarded should also be closely monitored and find ways to reduce or mitigate them. An example is the Ta precipitation unit. Despite water humidity and KF being almost $65 \%$ recirculated, due to the volumetric relation, high amounts of water are needed and a big part of this humidity is discarded and hence lost. Another critical unit is where the phase changes, in the "Liquid-Liquid extraction" unit. In this unit, an organic phase is introduced and an important amount of water and other elements in the water phase end up being discarded.

Until now, in Penouta, $\mathrm{Nb}$ and Ta ended up in tailings, but we have proofed that there are ways to recover a very significant amount of these elements annually. Looking 
for new and more sustainable paths to get the most out of the mines and recover metals more efficiently could be a way to overcome future shortages of elements, mineral depletion and decreasing ore grades, without compromising the environment.

Author Contributions: Conceptualization, F.A.L.; data curation, F.A.L. and F.J.A.; formal analysis, R.M.; investigation, R.M.; methodology, R.M.; writing-original draft, R.M.; writing - review and editing, G.C.; funding adquisition, A.V.; supervision, G.C.; A.V. and F.A.L. All authors have read and agreed to the published version of the manuscript.

Funding: This paper has received funding from the Spanish Ministry of Science and Innovation (PID2020-116851RB-I00 and RTC-2017-6629-5)

Acknowledgments: Thanks to Alejandro Abadías of Helmholtz Institute Freiberg for Resource Technology for the revision of the first draft of the paper. We acknowledge support towards the publication fee by the CSIC Open Access Publication Support Initiative through its Unit of Information Resources for Research (URICI).

Conflicts of Interest: The authors declare no conflict of interest.

\section{References}

[1] Smith L, Ibn-Mohammed T, Koh SCL, Reaney IM. Life cycle assessment and environmental profile evaluations of high volumetric efficiency capacitors. Appl Energy 2018;220:496-513. https://doi.org/10.1016/j.apenergy.2018.03.067.

[2] Calvo G, Valero A, Valero A. Material flow analysis for Europe: An exergoecological approach. Ecol Indic 2016;60:603-10. https://doi.org/10.1016/j.ecolind.2015.08.005.

[3] Ortego A, Calvo G, Valero A, Iglesias-Émbil M, Valero A, Villacampa M. Assessment of strategic raw materials in the automobile sector. Resour Conserv Recycl 2020;161:104968. https://doi.org/10.1016/j.resconrec.2020.104968.

[4] Valero A, Magdalena R, Calvo G, Ascaso S, Círez F. Eco-credit system to incentivise the recycling of waste electric and electronic equipment based on a thermodynamic approach. Int J Exergy 2021;32.

[5] Kumar V, Ramachandran D, Kumar B. Influence of new-age technologies on marketing: A research agenda. J Bus Res 2021;125:864-77. https://doi.org/10.1016/j.jbusres.2020.01.007.

[6] Jung SH, Feng T. Government subsidies for green technology development under uncertainty. Eur J Oper Res 2020;286:72639. https://doi.org/10.1016/j.ejor.2020.03.047.

[7] Calvo G, Valero A. Strategic mineral resources: Availability and future estimations for the renewable energy sector. Environ Dev 2021. https://doi.org/https://doi.org/10.1016/j.envdev.2021.100640.

[8] Smith Stegen K. Heavy rare earths, permanent magnets, and renewable energies: An imminent crisis. Energy Policy 2015;79:1-8. https://doi.org/10.1016/j.enpol.2014.12.015.

[9] Kitajima, Tomoaki; Sawanishi, Hideyuki; Taguchi, Masaya; Torihara, Kenta; Honma, Osamu; Mishima N. A proposal on a resource efficiency index for EEE. Procedia CIRP 2015;26:607-11. https://doi.org/10.1016/j.procir.2014.07.181.

[10] Parajuly, Keshav; Habib, Komal; Liu G. Resources , Conservation and Recycling Waste electrical and electronic equipment ( WEEE ) in Denmark: Flows , quantities and management. "Resources, Conserv Recycl 2017;123:85-92. https://doi.org/10.1016/j.resconrec.2016.08.004.

[11] Valero A, Valero A, Calvo G, Ortego A. Material bottlenecks in the future development of green technologies. Renew Sustain Energy Rev 2018;93:178-200. https://doi.org/10.1016/j.rser.2018.05.041.

[12] Xie F, Zhang TA, Dreisinger D, Doyle F. A critical review on solvent extraction of rare earths from aqueous solutions. Miner Eng 2014;56:10-28. https://doi.org/10.1016/j.mineng.2013.10.021.

[13] World Economic Forum. A New Circular Vision for Electronics Time for a Global Reboot. Platf Accel Circ Econ 2019;January:24.

[14] Hischier R, Wa P, Gauglhofer J. Does WEEE recycling make sense from an environmental perspective ? The environmental impacts of the Swiss take-back and recycling systems for waste electrical and electronic equipment ( WEEE ). Environ Impact 
Assess Rev 2005;25:525-39. https://doi.org/10.1016/j.eiar.2005.04.003.

[15] Gasik MI. Technology of Niobium Ferroalloys. Handb. Ferroalloys, Butterworth-Heinemann, 2013, p. 411-9. https://doi.org/10.1016/B978-0-08-097753-9.00014-9.

[16] Patel JK, Wilshire B. The challenge to produce consistent mechanical properties in Nb-HSLA strip steels. J Mater Process Technol 2002;120:316-21. https://doi.org/10.1016/S0924-0136(01)01130-X.

[17] Grandell L, Lehtilä A, Kivinen M, Koljonen T, Kihlman S, Lauri LS. Role of critical metals in the future markets of clean energy technologies. Renew Energy 2016;95:53-62. https://doi.org/10.1016/j.renene.2016.03.102.

[18] European Commission. Study on the EU's list of Critical Raw Materials (2020). Final Report. 2020. https://doi.org/10.2873/904613.

[19] Department of Industry I and S. Australia's critical minerals strategy. Australian Goverment. 2019.

[20] U.S. Department of Commerce. A Federal Strategy to Ensure Secure and Reliable Supplies of Critical Minerals, 2019.

[21] U.S. Geological Survey. Mineral commodity summaries 2021: U.S. Geological Survey. 2021. https://doi.org/https://doi.org/10.3133/mcs2021.

[22] Dutta SK, Lodhari DR. Niobium and Tantalum. Top Mining, Metall Mater Eng 2018:219-28. https://doi.org/10.1007/978-98110-5172-2_20.

[23] Valdés DA, Bustamante N. ANÁLISIS DESCRIPTIVO DEL COLTÁN EN COLOMBIA Y SUS POSIBLES MERCADOS POTENCIALES. Trab Grado 2010;Centro de:43.

[24] Schütte P, Näher U. Tantalum supply from artisanal and small-scale mining: A mineral economic evaluation of coltan production and trade dynamics in Africa's Great Lakes region. Resour Policy $2020 ; 69$. https://doi.org/10.1016/j.resourpol.2020.101896.

[25] Bleischwitz R, Dittrich M, Pierdicca C. Coltan from Central Africa, international trade and implications for any certification. Resour Policy 2012;37:19-29. https://doi.org/10.1016/j.resourpol.2011.12.008.

[26] Nathan D, Sarkar S. Blood on your mobile? Econ Polit Wkly 2010;45:22-4.

[27] Group of Experts on the Democratic Republic of the Congo. Final Report 2010.pdf 2010;61506:191.

[28] Van Bockstael S. The emergence of conflict-free, ethical, and Fair Trade mineral supply chain certification systems: A brief introduction. Extr Ind Soc 2018;5:52-5. https://doi.org/10.1016/j.exis.2017.12.014.

[29] Calvo M. Minerales y minas de España. Volumen IV: óxidos e hidróxidos. Prames; 2009.

[30] Marina EF, Guzmán VF. The mining industry in Spain. Madrid: IGME; 1987.

[31] Magdalena R, Valero A, Palacios JL, Valero A. Mining energy consumption as a function of ore grade decline: the case of lead and zinc. J Sustain Min 2021;20:109-21. https://doi.org/https://doi.org/10.46873/2300-3960.1060.

[32] Palacios JL, Abadias A, Valero A, Valero A, Reuter MA. Producing metals from common rocks: The case of gold. Resour Conserv Recycl 2019;148:23-35. https://doi.org/10.1016/j.resconrec.2019.04.026.

[33] Palacios JL, Fernandes I, Abadias A, Valero A, Valero A, Reuter MA. Avoided energy cost of producing minerals: The case of iron ore. Energy Reports 2019;5:364-74. https://doi.org/10.1016/j.egyr.2019.03.004.

[34] López-Moro FJ, García Polonio F, Llorens González T, Sanz Contreras JL, Fernández Fernández A, Moro Benito MC. Ta and Sn concentration by muscovite fractionation and degassing in a lens-like granite body: The case study of the Penouta raremetal albite granite (NW Spain). Ore Geol Rev 2017;82:10-30. https://doi.org/10.1016/j.oregeorev.2016.11.027.

[35] Ghorbani Y, Fitzpatrick R, Kinchington M, Rollinson G, Hegarty P. A process mineralogy approach to gravity concentration of tantalum bearing minerals. Minerals 2017;7. https://doi.org/10.3390/min7100194.

[36] Shikika A, Sethurajan M, Muvundja F, Mugumaoderha MCC, Gaydardzhiev S. A review on extractive metallurgy of tantalum and niobium. Hydrometallurgy 2020;198:105496. https://doi.org/10.1016/j.hydromet.2020.105496.

[37] López FA, García-Díaz I, Largo OR, Polonio FG, Llorens T. Recovery and purification of tin from tailings from the Penouta Sn-Ta-Nb deposit. Minerals 2018;8:1-13. https://doi.org/10.3390/min8010020.

[38] Rodríguez O, Alguacil FJ, Baquero EE, García-Díaz I, Fernández P, Sotillo B, et al. Recovery of niobium and tantalum by 
solvent extraction from Sn-Ta-Nb mining tailings. RSC Adv 2020;10:21406-12. https://doi.org/10.1039/d0ra03331f.

[39] Allain E, Kanari N, Diot F, Yvon J. Development of a process for the concentration of the strategic tantalum and niobium oxides from tin slags. Miner Eng 2019;134:97-103. https://doi.org/10.1016/j.mineng.2019.01.029.

[40] Subramanian C, Suri AK. Recovery of Niobium and Tantalum from Low Grade Tin Slag - A Hydrometallurgical Approach. Environ Waste Manag 1998:100-7.

[41] Outotec. OUTOTEC HSC CHEMISTRY SOFTWARE 2020:1. https://www.outotec.com/ (accessed December 4, 2019).

[42] Valero A, Valero A, Martínez A. Inventory of the exergy resources on earth including its mineral capital. Energy 2010;35:98995. https://doi.org/10.1016/j.energy.2009.06.036.

[43] Valero A, Valero A. Thanatia: the destiny of the Earth's mineral resources. Zaragoza: World Scientific Publishing; 2014.

[44] M. Latva-Kokko, T. Hirsi, T. Ritasalo and JT. Improving the process performance of gold cyanide leaching reactors. South African Inst Min Metall 2015:1-11.

[45] Christie T, Brathwaite B. Mineral Commodity Report 6 - Lead and Zinc. New Zeal Min 1995;16:22-30.

[46] Odo JU, Okafor WC, Ekpe SO, Nwogbu CC. Extraction of Niobium from Tin Slag. Int J Sci Res Publ 2014;4:1-7. 